\title{
EXOMORPHOGENESIS OF COSMOGENIC RING STRUCTURES OF KAZAKHSTAN
}

\author{
LARYSA VESELOVA, KHAINI-KAMAL KASYMKHANOVA, UMUT KOZHAKHMETOVA, \\ ROZA BEKSEITOVA, IRINA SHMAROVA, RAHAT TURAPOVA, \\ GULBAN BAYDAULETOVA
}

Cartography and Geoinformatic Department of al-Farabi, Kazakh National University

*Corresponding author e-mail: hkasymkanova@gmail.com

Received: $2^{\text {nd }}$ August 2018, Accepted: $2^{\text {nd }}$ January 2019

\begin{abstract}
The use of materials for remote sensing of the Earth made it possible to identify a new type of crustal structures and features of their expression in relief. These are ring structures that complicate the structure of the studied structures of a linear type. As a result of the study of the morphology, geological and tectonic structure of ring structures, it was established that they represent formations of various origins: pluton-volcanic, cosmogenic, and anthropogenic. Cosmogenic structures of different ages and differ in various degrees of transformation.

The relief of the identified cosmogenic structures within the limits of the Turan Plains, the Kazakh small hills and mountains of South-Eastern Kazakhstan is transformed by exogenous processes. The defining indicator features of cosmogenic structures include geomorphological, geological, structural tectonic, and also landscape. The degree of change in the initial cosmogenic relief depends on the time of formation, paleogeographic and modern physiographic conditions of the territories. Under the arid conditions of Kazakhstan's epyhercynian platform, the main factor in the preservation of the "primary" morphology of meteorite craters is the lithologic stratigraphic complexes of the ring shaft. For the studied cosmogenic structures, in particular, the meteorite craters of Saryarka, a distinct geodynamic zoning of the development of exomorphogenesis processes is characteristic. The main exogenous processes include gravity-slope, surface washout, ravine and river erosion, processes of complex denudation and accumulation. The factors and processes of creating a modern crater relief morphology are established.

These studies of cosmogenic ring structures of Kazakhstan have not only theoretical significance, revealing the role of cosmogenic processes of the formation of the Earth as a planet, but also have immediate practical importance. Meteorite craters are indicators of mineral deposits.
\end{abstract}

Keywords: ring structures, cosmogenic structures, meteorite craters, ring faults, exomorphogenesis factors, exogenous processes, water erosion, landslides, indicators of the field of mineral deposits. 


\section{INTRODUCTION}

The use of remote methods for studying the earth's surface allowed us to expand our knowledge of its structure. This applies primarily to questions about the structures of the earth's crust, their expression in the relief of the Earth, about the origin and diversity of morphostructures within the platform and mountainous areas.

Modern research methods allow us to study our planet as a single mechanism, a global level system, to objectively consider natural processes, both as a whole and in interaction. This applies primarily to the study of tectonic structures. In addition to well-studied linear-type structures, numerous circular structures are clearly visible on satellite images of the Earth's surface.

As a new type, ring structures were identified on the territory of Kazakhstan only in the 60-70s of the XX century. The first ring structures are determined as a result of the application of complex methods of morphostructural relief analysis. The pioneering studies on mapping ring structures in Central Kazakhstan are associated with the names of well-known geologists and geomorphologists: B.S. Zeilik, G.Z. Popova, N.V. Skublova, E.Yu. Seitmuratova and others.

The most difficult theoretical and methodological issue is the origin of ring structures. The data of more than 50 years of study confirms the position of three types of ring structures: pluton-magmatic, cosmogenic and anthropogenic. According to G.Z. Popova (Popova, 1966) ring structures of the first type were formed as a result of the manifestation of magmatic processes (effusive and intrusive).

The second genetic type of ring structures formed as a result of meteorites falling to the surface of the Earth. These are cosmogenic ring structures (CRS). The formation of these structures is considered from the standpoint of shock-explosive tectonics (Zeylik, 1991).

Numerous ring-shaped relief forms of exogenous and technogenic genesis are related to anthropogenic ring structures.

Currently in Kazakhstan, special attention is paid to the study of cosmogenic structures identified within the limits of the Turan Plains, the Kazakh small hills and mountains of South-Eastern Kazakhstan. The first well-studied meteorite crater is the Zhamanshin cosmic ring structure (Florensky \& Dabizha, 1980; Rozhdestvensky et al., 1991; Zeilik, 1976; Masaytis, 1980, 2000; Khryanina, 1987; Zeilik, 1991).

In 1939 V.A. Vakhromeev and A.L. Yanshin were working in the Northern Aral Sea region, they drew attention to a small territory in the area of the Zhabynyntau mountains, where Paleozoic metamorphic rocks are found on the surface among Paleogene gray clays. In 1960, during a geological survey, B.V. Pilia discovered small glasses and slags in this area, later called the Zhamanshin tract, which P.V. Florensky began to study. The study showed that these rocks are formed as a result of the fall of meteorites. This was the basis for determining the origin of the tract Zhamanshin as a meteorite crater. Thus, for the first time in the world, tektites called P.V. Florensky by irgitsites along the Irgiz River, which flows $15 \mathrm{~km}$ north-east of the crater (Florensky, 1980), were discovered directly in the meteorite crater.

Zhamanshin Meteor crater aroused great interest of researchers. In 1960-70 a comprehensive program for the study of the crater, Zhamanshit and Irgizites was developed, in which scientific organizations of the USSR, Austria, the USA, the FRG and the CSSR took part.

Research has begun to seek minerals associated with cosmogenic ring structures (Zeilik, 2004; Popova, 1966; Baratov, 2012; Veselova, 2014).

Data on the geomorphological structure of the Zhamanshin crater is given in the article by geomorphologists A.P. Rozhdestvensky, D.A. Timofeev, I.K. Zinyakhin and Yu.L. 
Kisareva. In conclusion, they note that the Zhamanshin meteorite crater was formed in the post-Early Pleistocene time or at the end of it (Rozhdestvensky, 1991).

An analysis of the published materials has shown that when studying meteorite craters, the processes of exomorphogenesis, the main factors of transformation (destruction) of the geomorphological system of cosmogenic ring structures are not studied at all.

The purpose of our research was to identify the features of the development of exomorphogenesis processes of cosmogenic structures - meteorite craters of the arid zone of Kazakhstan, the degree of their transformation and preservation on the example of Shunak crater.

\section{INITIAL DATA AND RESEARCH METHODS}

The basis of the initial data of the study and mapping of exomorphogenesis processes are published materials of geological and geographical research, remote sensing of the Earth, the results of our field studies of the relief and landscapes of Kazakhstan.

In 1976, B.S. Zeylik published an article suggesting that Shunak could be a meteorite crater. A year later, this assumption was confirmed by a team of famous scientists (Masaytis et al., 1980; Khryanina, 1987): the geological structure of the Shunak structure was clarified and petrographic and mineralogical signs of a meteorite impact were established (Zeilek, 2004; Masaytis, 1980; Khryanina, 1987).

The formation of cosmogenic ring structures is currently being considered from the standpoint of shock - explosive tectonics (Zeylik, 1991). On the basis of a comprehensive study of satellite images of the Earth's surface of various resolutions, creating models of morphological, geological, geochemical, tectonic structures, studying cosmogenic ring structures directly in the field, "the Map of ring structures of our planet"was compiled.

The beginning of XXI century is marked by the discovery on the surface of the Earth of more and more new cosmogenic structures, as well as the fixation of the fall of meteorites in our time. An example is the Chelyabinsk meteorite (February 15, 2013). Separate results were obtained from studies of meteorite fragments and the morphology of the place of fall (Celmovich, 2014). There is a significant heterogeneity of the fallen meteorite. The main part of it is related to ordinary chondrites. At the same time, the presence of the pure iron rare for meteorites with fragments of silicates and a high content of titanium, which is rarely found in one meteorite, was revealed (Taskaev, 2014; Ogliore,2013).

In the territory of Kazakhstan, the crater Bigach and the crater Chiyli should be attributed to the newly identified cosmogenic structures. These craters, like the crater Zhamanshin and Shunac, are included in the global database "Earth impact Database: University of New Brunswick".

Crater Chiyli was recorded in Kazakhstan by NASA satellite in 2007. The satellite images clearly show the image of the crater in the Aktobe region (coordinates: 49010' 30" N 570 50 ' 6" E) within the stepped denudation plain of the Turan plate. It is $5.5 \mathrm{~km}$ diameter over $7 \pm 7$ million years. It should be noted features of this crater: the inner ring of the crater is at a higher level than the outer. Such a morphology is the characteristic of numerous flat-topped elevations - the northern turkkuls of the Aral region, which were formed as a result of the dismemberment of the Paleogene-Neogene plain under the conditions of the neotectonic uplifts of the pluvial period of Kazakhstan and Central Asia. Turtkuli recorded on geomorphological maps as a result of field geological and geomorphological studies. The results of studying the geological structure of this crater are unknown to us. In this regard, we believe so far that the cosmogenic structure of Chiyli can be a turkkul. One of the confirmations may be the peculiarities of the modern morphology of Zhamanshin crater, 
located in the dry steppe zone. Moreover, the expected age of Chiyli is about the same as Zhamanshin.

Crater Bigach is located on the territory of the East Kazakhstan region (coordinates: 48034' $\mathrm{N} 8201$ ' E) within the lowlands of the Kalbinsky ridge. It is $5 \pm 3$ million years. The crater morphology, according to the research, is disturbed by the latest tectonic movements. The crater currently does not represent an annular structure, since some parts of the annular shaft are displaced along faults and the crater has a somewhat elongated (deformed) shape. The recovered approximate diameter of the crater is about $8 \mathrm{~km}$. Well-defined inner surface - the bottom of the crater, which is used for agricultural purposes.

Kazakhstan is characterized by the intensification of studies of cosmogenic ring structures of mountain areas, in particular, Rudny Altai (Chikov, 2011).

Currently, there is an intensification of studying cosmogenic ring structures, not only in terms of geology, but also a number of geographic and environmental disciplines. Much attention is paid to the issues of large-scale mapping of ring structures. In this regard, the report of V.L. Maitis on the VIII All-Russian Congress of Geologists: «. the mapping of the impact structure as a specific object with morphological, structural and material expression can be performed on the basis of its accurate diagnosis, determining the composition and conditions of occurrence of formations of the coptogenic complex» (2016) must be noticed.

Our research was concentrated within the Kazakh shield. They include three interrelated stages: geographical, cartographic, and geological. Each of them used a set of methodological techniques based on the use of the main laws of the system analysis of the relief.

The geographical stage of the research consisted in identifying the spatial position of cosmogenic structures — meteorite craters. Its constituent part is geomorphological methods, which make it possible by geomorphological indicators to determine the origin of the ring structure, to study the morphology, morphometric characteristics, structure of modern exomorphogenesis processes. New data were obtained as a result of applying the paleogeographic research method.

In this case, the cartographic method was used to obtain information on the identification of patterns of distribution of the processes of exomorphogenesis of the Shunak crater based on the interpretation of satellite images, the study and analysis of Earth remote sensing materials, and the compilation of landscape maps of Saryarka.

Lithologic stratigraphic data were obtained as a result of analysis of published and stock materials of geological studies of cosmogenic ring structures of Kazakhstan. Lithology of rocks determines the morphology of the relief, is the basis of the geomorphological landscape. Rocks have different properties: resistance to external forces (exomorphogenesis factors), permeability, solubility, subsidence, etc. The manifestation of these properties depends on the physiographic conditions, especially the climate.

The distribution of lithologic-stratigraphic complexes of rocks in space corresponds to the position of the main tectonic structures. Thus, the Precambrian and Paleozoic crystalline rocks participate in the geological structure of the Kazakh shield and orogenic structures of Southeastern Kazakhstan. The geological formations of the Turan plate are represented by Mesozoic and Cenozoic sedimentary rocks. This regional geological pattern of distribution of lithologic and stratigraphic complexes is subject to the development of exomorphogenesis processes in Kazakhstan, including within cosmogenic ring structures.

One of the tasks of studying cosmogenic structures as relief forms is the study of their morphology, the preservation of the "primary" elements of meteorite craters in certain physiographic conditions. 
Conventionally, there are three main stages in the study of exogenous processes that alter and transform the crater morphology. Litho-stratigraphic complex, geological-tectonic, climatic and biogenic factors are among the leading factors of transformation, changes in the "primary" crater morphology. Their relief-forming role is diverse and subject to both general and regional spatial-temporal patterns. This position is most vividly expressed in the modern morphology of the relief elements of the meteorite craters of the Kazakh shield (Shunak crater) and the Turan plate (Zhamanshin crater).

We tried to find out with what intensity the changes (destruction) of the "initial" morphology of the relief of the crater Zhamanshin and Shunak occur, located in the same landscape-climatic zone, but formed by different lithologic - stratigraphic complexes.

The formation time of these cosmogenic ring structures is almost the same. Both craters are located in the semi-desert zone. However, the degree of transformation of the crater topography by exomorphogenesis processes is completely different. This is most clearly expressed when comparing the morphology of the relief of craters Zhamanshin and Shunak (Fig.1).

Fig. 1: General view of the modern relief of Shunak and Zhamanshin craters. LANDSAT space images
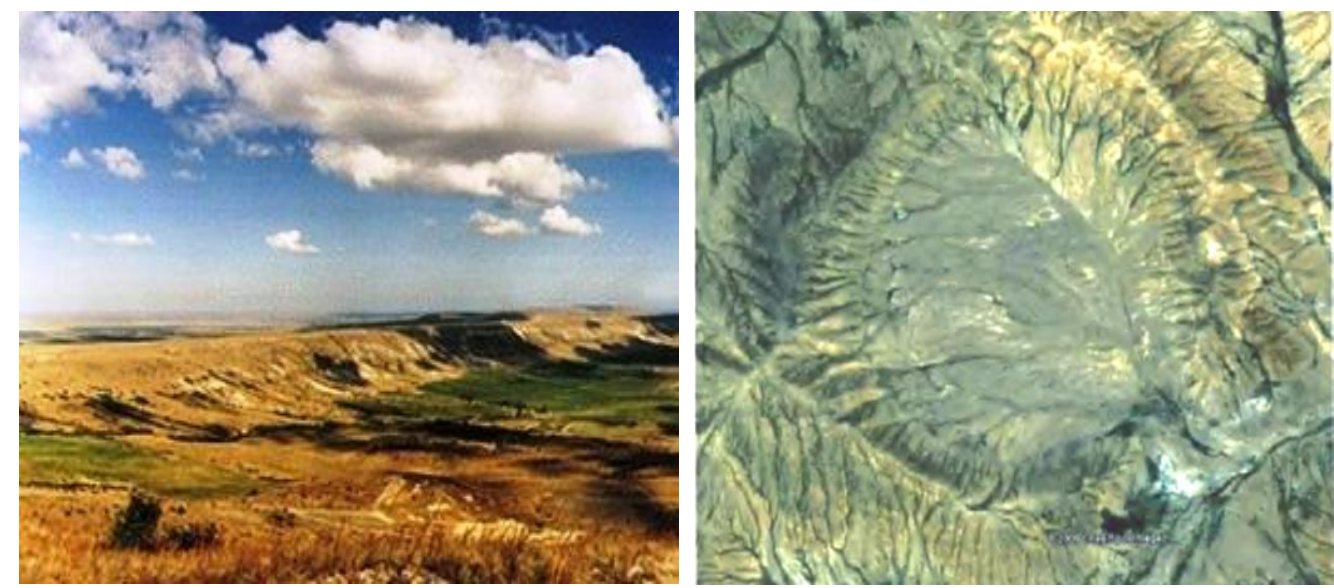

Especial differences are observed in the structure of the ring shaft. The integrity of the annular shaft crater Zhamanshin is broken. It is represented by a system of multi-height steep slopes of crest, ridges, hills formed as a result of erosion, gravity-slope processes. This was facilitated by the composition of rocks, their influence on the intensity of the development of exomorphogenesis processes. The ring shaft of the crater is distinguished by a complex lithologic-stratigraphic complex. In the geological section of the shaft, two parts are clearly expressed. The lower part consists of fragments of Paleogene, Cretaceous and Paleozoic rocks that overlap the undisturbed Paleogene rocks. The upper part of the annular shaft (Coptogenic complex) includes allogeneic breccia and impactites: irgizites, zhamanshits with fragments of Paleozoic rocks. The imhomogeneity of the lithological composition of the ring shaft has become the main factor of its intensive transformation, destruction (Izokh, 1990).

Absolutely excellent lithology of rocks, which determines the morphology of the relief of the annular shaft and all elements of the Shunak crater, located in the same landscape and climatic conditions as Zhamanshin. These questions are discussed in the next section. 


\section{RESULTS AND DISCUSSIONS}

Unique cosmogenic ring of Shunak structure is located in Central Kazakhstan, $40 \mathrm{~km}$ west of the Mointy railway station between the Bayaulysay and Altivay Rivers. On the plan of it, it represents a low mountain ring surrounded by a denudation plain. For a long time (until 1979), the Shunak ring structure was considered a Devonian paleovolcan. The main reason was the absence of allogeneic breccia and other impact rocks on the surface of the annular shaft, i.e. there was no loose shaft overlapping the basement. However, detailed geological, petrographic and mineralogical studies, as noted above, were confirmed by B.S. Zeylika that Shunak is a meteorite crater.

In the structure of the crater, the following morphological elements are distinguished, which are perfectly deciphered on satellite images: the ring shaft and the bottom of the crater (Fig. 1). Ring shaft is a lowland with a height of $600 \mathrm{~m}$ above the crater bottom. The diameter of the crater on the shaft is about $3.0 \mathrm{~km}$, and the internal $2.1 \mathrm{~km}$. The geological structure of the annular shaft is not typical. Here only the socle lithologic and stratigraphic complex is presented. The morphological structure of the basement shaft is asymmetric: the inner slopes are steep $\left(30^{\circ}-70^{\circ}\right)$, the outer gentle slopes are up to $15^{\circ}$. The inner slopes of the crater are dissected by numerous channels of first-order water flows, which form valleys of the second order in the middle part of the slope. The main river, dividing the bottom of the crater, refers to the rivers of the third order. The main role in erosion processes belongs to temporary seasonal (snow and rain) waters. In general, within the crater, the river network forms a single fluvial system, including sections of crater valleys of tectonic and erosion genesis.

Lowlands or basement shaft of Shunak crater formed in Devonian effusions of the Kazakh shield. On the slopes of the basement shaft, as well as on the denudation plain surrounding the crater, there are various formations associated with the fall of the meteorite: allogeneic and authigenic breccia. They are also opened at the bottom of the crater wells.

The main tectonic violations of the crater are ring faults and grabens, which in modern relief are clearly recorded by the system of drawing of the hydrographic network.

The second morphological element of the Shunak cosmogenic system is, as noted above, the bottom of the crater. It is an alluvial-proluvial plain, slightly inclined to the south-east, composed of quaternary loams and sandy loams with a capacity of up to $5 \mathrm{~m}$. Quaternary sediments cover the Neogene clays, which are sediments of the Paleozerian Shunak. These elements of the crater morphology are clearly expressed in relief (Fig. 1).

The morphogenetic and morphometric characteristics of the elements of the cosmogenic relief, the geological and tectonic structure of the Shunak crater, its geographical location determined the uniqueness of the planned and morphological structure of landscapes and the exomorphogenesis processes developing in them. The main regularity of their spatial position is concentricity and altitudinal zonation. Within the outer slope of the ring shaft of the Shunak crater, steppe landscapes with white-pollen-fescue-feather grass vegetation dominate on mountain light-chestnut soils.

The landscape structure of the internal crater slope is more complex than the external: along with the tracts of bedrock exposures, numerous ravines, logs, landslides, ravines and ravines are well developed.

The landscape of the crater bottom - alluvial-proluvial plain is represented by meadow-steppe vegetation on the alluvial soils of the river system. Tracts of linearly oriented depressions confined to tectonic fractures prevail.

This structure of the landscape of the ring shaft and the bottom of the Shunak crater determines the genetic and spatial differentiation of modern relief formation processes.

In cosmogenic crater forms, in our opinion, the spatial and temporal structure of their change should be emphasized. The time factor affects the sequence of complications of the 
cosmogenic structure, as well as the intensity of the manifestation of the processes of their change, the weathering of chondrites, suvits occurs (Efremov, 1999; Dmitriev, 2001; Kalleson, 2010; Zurfluh, 2016). This made it possible to present the following temporal model of the transformation of the relief of a crater: weathering $\rightarrow$ gravity-slope processes $\rightarrow$ plane wash $\rightarrow$ linear erosion $\rightarrow$ complex accumulation.

The main exogenous factors that transform and complicate the structure of exomorphogenesis processes include precipitation and groundwater. It has been established that the runoff of rainfall for rocks, which form an annular basement shaft of the crater, averages 0.20 for the flow coefficient, and for loose rocks, the value for the flow coefficient varies from 0.04 to 0.30 .

The above temporary model of relief transformation processes will be considered for the following elements of the Shunak crater system - the annular shaft, the slopes and the bottom of the crater. Crater exomorphogenesis processes are a single geomorphological system.

In conditions of arid climate of the territory of the Kazakh small hills, the processes of physical weathering, complex denudation, are developing everywhere. However, within the crater system, processes due to the activity of water flows prevail. Gravitational - slope processes are also intensively developed: landslides, rockfalls, debris. They prevail within the inner slope of the annular shaft and the crater slope, forming accumulative relief forms at the piedmont. The distribution of exomorphogenesis processes on the slopes of the crater has a ring character. The distribution of exomorphogenesis processes on the slopes of the crater has a ring character. The following internal exodynamic zones of the crater were identified: eluvial, erosion-denudation, transit, complex slope accumulation, fluvial accumulative-erosion (Fig. 2).

Fig. 2: Exodynamic zones of the Shunak crater.

1- eluvial, 2 - erosion-denudation, 3 - transit, 4 - complex slope accumulation, 5 - fluvial accumulative erosion

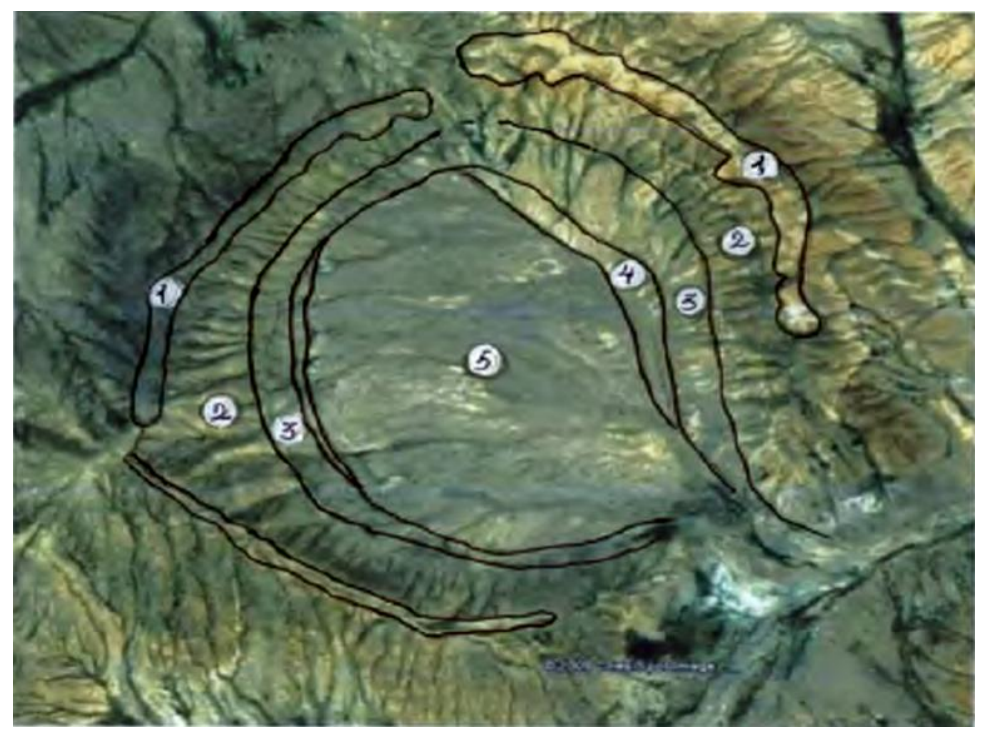

The main processes of the modern transformation of the crater relates to the activity of water flows. Water streams, as mentioned above, form a fluvial system consisting of the main river (third order) and numerous tributaries of the first and second orders. In addition, 
$\mathrm{V}$-shaped valleys of temporary streams are widely developed, dividing the slopes of the annular shaft into separate ridges, manes. On the inner slopes of the crater there are numerous landslides.

At the foot of the slopes of the crater, complex accumulation processes are developed: debris cones, landslides, scree. The main accumulative landform is the alluvial-proluvial plain, representing the bottom of the crater. Its surface is dissected by the river system. The riverbed is confined to a tectonic fault that crosses the crater at the northeast foot of the annular shaft. Unlike the left tributaries, the sources of the right numerous tributaries are the springs at the foot of the crater. The river to the southeast at the exit from the crater within the annular shaft forms an antecedent valley.

Thus, the fluvial processes intensively change and complicate the "initial" morphology of the meteorite crater.

When analyzing the data of studying the exomorphogenesis processes of the Shunak crater, the question arose of the presence and preservation of donogenic weathering crust (Fig 1). Palegeographic analysis allowed us to present the following concept of reconstruction of individual moments of formation and development of this cosmogenic structure.

First: the presence of the donogenic weathering crust on the surface of the annular shaft indicates that during the fall of the meteorite the relief of Central Kazakhstan was a donogenic peneplain. In the Neogene, the crater became a lake basin, as evidenced by lake Neogene deposits exposed by wells.

Second: the manifestation of the newest (Neogene-Quaternary) tectonic movements along the ring and linear faults became the main factors raising the annular shaft to an absolute height of 1000-1100 $\mathrm{m}$ and preserving donogenov peneplen relics on its apical surface covered with weathering crust. The absolute height of the donogen peneplain during the fall of the meteorite was about $500 \mathrm{~m}$. Thus, the height of the annular shaft increased by $500-$ $600 \mathrm{~m}$. This was the main reason for the lack of a loose shaft as a result of the development of denudation processes during the period of tectonic uplifts of the territory along ringed tectonic faults. This process is still ongoing. The area of the top surface of the annular shaft with relics of the weathering crust of the donogenic peneplen gradually decreases.

Presented research materials were discussed at international and republican conferences. (2006; 2010; 2014; 2015; 2017).

\section{CONCLUSION}

As a result of research, it has been established that the development of exomorphogenesis processes in cosmogenic ring structures, as in natural mountain systems, corresponds to the law of altitudinal zonation.

The main processes of exomorphogenesis of meteorite craters in the arid zone of Kazakhstan are fluvial processes.

A paleogeographic analysis of the geomorphological system of the cosmogenic ring structure made it possible to present the concept of reconstruction of the development of individual morphological relief elements, crater deposits in the Neogene-Quaternary time.

Cosmogenic ring structures are a search sign of rare-metal, gold and polymetallic deposits of Central Kazakhstan.

Further study and mapping of cosmogenic structures is necessary not only from the point of view of geology, the forecast of mineral deposits, but also from the point of view of geomorphology, landscape science, ecology, tourism.

Cosmogenic ring structures are informative objects of educational tourism, which require further development in Kazakhstan. 


\section{REFERENCES}

Baratov, R.T., Bakdauletkyzy, S., Dautbekov, D.O. (2012). Indicator signs of ring structures of different Genesis. Actual problems of modern Geology and Mineralogy of Kazakhstan. Materials of the international scientific-practical conference "Satpayev readings", dedicated to the day of scientists. 12-14 April 2012. - Almaty: 2012. - P. 497-505.

Veselova, L.K., Kozhahmetova, U.K. (2014). Ring structures of Central Kazakhstan and their connection with mineral deposits. Cartography and geodesy in the modern world. Materials of the second all-Russian scientific-practical conference. Saransk: publishing house of the University of Mordovia, 2014. -P. 80-84

Dmitriev, E. V. (2001). Tektites, sunteccity, striperplay the Tunguska meteorite. Nature. 2001, №1. P. 31-32

Zejlik, B.S. (2012). New technology of construction of maps of mineral deposits prediction based on the principles of shock-explosive tectonics (UHT) and remote sensing data. Actual problems of modern Geology and Mineralogy of Kazakhstan. Materials of the international scientific-practical conference "Satpayev readings", dedicated to the day of scientists. 12-14 April 2012. Almaty: 2012. - P. 486-497.

Zejlik, B.S. (1991). Shock-explosive tectonics and a brief sketch of plate tectonics. Alma-Ata, 1991. - $120 \mathrm{p}$.

Zejlik, B.S., Tyugaj, O.M., Gurevich, D.V., Omarov, B.S. (2004). Cosmogeological map of Kazakhstan m-ba 1: 1500000 and the problem of space protection of the planet to save life on Earth. Materials of the XXXII International geological Congress in Florence. Italy. 2004.

Zeylik, B. S., Urazaeva, S. B., Petrovsky, V. B., Seitmuratova, E. Y., Esbulatova, Z. M. (2008). Cosmogeological map of Kazakhstan m-ba 1: 1000000, forecast of mineral deposits and the problem of space protection of the planet to save life on Earth. Proceedings of the XXXIII International geological Congress in Oslo, Norway, 2008.

Izokh, E. P., Kashkarov, P. P., Geneva, L. I. (1990). The age of the glasses of the impact crater Zhamanshin according to the track research. Traces of space impacts on the earth.Sat.scientific papers. Novosibirsk: Science, 1990. - P. 188-193

Evremov, YU.V. (1999). Shock (impact) processes and morpholithogenesis. Geomorphology, 1999, № 2. - P. 12-21

Engalychev, S. Y. (2009). Svetloyar - new impact structure on the territory of European Russia. Exploration and protection of mineral resources. 2009. № 8. -P. 3-7

Masajtis, V.L., Danilin, A.N., Mashchak, M.S. (1980). Geology of astroblems. L.: Subsoil, 1980. $-231 \mathrm{p}$.

Masajtis, V.L. (2016). On geological mapping of impact structures. Regional Geology and metallogeny. 2016, № 67, - P. 61-69

Popova, G.Z. (1966). Ring and linear morphostructures of the Kazakh folded country. Alma-Ata: Science Kaz. USSR, 1966. - 206 p.

Rozhdenstvenskij, A.P., Timofeev, D.A., Zinyahina, I.K., Kisarev, YU.L. (1991). To the geomorphology of the area of the meteorite crater Zhamanshin. Geomorphology, 1991. № 2. - P. 78-86.

Taskaev, S.V., Galimov, D.M., Stallions, D.A., Khovaylo, V.V., Gorshenkov, M.V., Vasilyev, N.N., Golovanov, A.N., Volkova, O.S., Timoshenko, V.Y. (2014). Multispectral 
studies of fragments of the Chelyabinsk meteorite. Bulletin of the Chelyabinsk state. Un-ta, 2014, № 1. Physics. Vol.19. - P. 68-87

Florenskij, P.V., Dabizha, A.I. (1980). Meteorite crater Zhamanshin. M.: Science, 1980. -128 p.

Hryanina, L.P. (1987). Meteorite craters on Earth. M.: Subsoil. 1987. - 112 p.

Selimovic, V., Gindilis, L.M., Shevelev, G.N. (2014). Analysis of the magnetic fraction in the dust component of the Chelyabinsk meteorite. Chelyabinsk Meteorite-year on Earth. Mat-ly vseros.scientific. Conf. Chelyabinsk: Chelyabinsk regional Agency for CIP, 2014. -P. 301-307

Veselova, L.K., Bexeitova, R T., Kassymkanova, K.-K., Duisebaeva, M., Kulzada, Zh., Turapova, R. O., Tumazhanova, S.O., Taukebaev, O.Z. (2001). Altitudinal Zonation of Exomorphogenesis in Northern Tien Shan. IEJME- Mathemanics Education 2016, VOL. 11, № 7, 1987. -2001.

Zurfluh, F.J., Hofmann, B.A. (2016). Weathering of ordinary chondrites from Oman: Correlation of weathering parameters with14C terrestrial ages and refined weathering scale. GnosEdmin, Eggenberger Urs et al. Meteorit and Plonet. Sci. 2016. 51, № 9, c.1685-1700.

Bekseitova, R.T., Veselova, L.K., Koshim, A.G., Kozhahmetova, U.K. (2014). Morho-orographic and morho-clinic factors exormrphical of platform-denudation plains of Kazahstan. Life Science Journal 6 2014, 11 (10s). P. 243 - 249.

Kalleson Erin, Dypvik Henning, Nilsen Odd. Melt-bearing impactites (suevite and impact melt rock) within the Gardnos structure Norway. Meteorit and Planet. Sci, 2010. 45, № 5, c.789-827.

Masaitis, V.L. (2005). Morpological, structural and lithological records of terrestrial impacts: an overview. Australian J. of Earth Sci.2005.Vol.52. No4/5. -P.509-528

Martini, J.E.J. (1978). Coesite and stishovite in the Vredefort Dome. South Africa. Nature. 1978. V. 272, N 5655. P. 715-717.

Ogliore, R.C. (2013). Gigapixel oftical microscopy for meteorite characterization. R.C. Ogliore, Ch.E. Jil-ly. Planetary Science. 2013. Vol. 2 P. 3 (1-10)

https: // wikipedia. Org/wiki/Category: Impact_of Kazakstan. 